1 This is a pre-accepted version, please cite this paper:

2 Wang, L.L., Tang, C.S., Shi, B., Cui, Y.J., Zhang, G.Q. and Hilary, I., 2018.

3 Nucleation and propagation mechanisms of soil desiccation cracks. Engineering

4 Geology, 238, pp.27-35. 


\title{
Nucleation and propagation mechanisms of soil desiccation cracks
}

\author{
Lin-Lin Wang ${ }^{1}$, Chao-Sheng Tang ${ }^{2 *}$, Bin Shi $^{3}$, Yu-Jun Cui ${ }^{4}$, Guang-Qing Zhang ${ }^{5}$, Inyang Hilary ${ }^{6,7}$
}

1. Professor, State Key Laboratory of Petroleum Resources and Prospecting, China University of Petroleum (Beijing), 102249, Beijing, P.R. China. E-mail: linlin.wang@cup.edu.cn

2. Professor, School of Earth Sciences and Engineering, Nanjing University, Nanjing 210023, P.R. China.

E-mail: tangchaosheng@nju.edu.cn

3. Professor, School of Earth Sciences and Engineering, Nanjing University, Nanjing 210023, P.R. China.

E-mail: shibin@nju.edu.cn

4. Professor, Laboratoire Navier-CERMES, Ecole des Ponts ParisTech, 77455 Marne-la-Vallée cedex 2, France. E-mail: yujun.cui@enpc.fr

5. Professor, College of Petroleum Engineering, China University of Petroleum (Beijing), 102249, Beijing, P.R. China. E-mail: zhang0@263.net

6. Professor, School of Earth Sciences and Engineering, Nanjing University, Nanjing 210023, P.R. China. E-mail: h.inyang26@gmail.com

7. President, Global Education and Infrastructure Services Inc., Charlotte, NC, USA \& Abuja, Nigeria

\section{*Corresponding author:}

Professor Chao-Sheng Tang

School of Earth Sciences and Engineering, Nanjing University, Nanjing 210023, China.

E-mail: tangchaosheng@nju.edu.cn 
1 Abstract: Contraction of soil during desiccation gives rise to polygon-patterned cracking. This

2 phenomenon was investigated by continuous full-strain measurements on soil sample surfaces using

3 digital image correlation techniques. The results show that desiccation cracking was of the mode I

4 variety and can be reliably predicted through strain field analyses: the observed cracking was restricted

5 mostly to high stretching domains. The observed high stretching stems from either external restraint or

6 internal flaws of the shrinking soil. The cracks redistribute the stress in their vicinity and lead

7 neighboring cracks to intersect them mostly orthogonally. As desiccation proceeds, the surface strain

8 field ceases to provide useful information for predicting crack locations. Further analysis indicates that

9 although drying occurs from exposed material surfaces, late-generation cracks actually initiate in the 10 subsurface and express themselves subsequently at the surface. These observations offer insights into 11 the intrinsic mechanisms of drying-induced crack growth in soils.

12

13 Keywords: Soil desiccation cracking; Drying shrinkage; Digital image correlation; Full-field strain 14 measurement; Crack pattern 
Desiccation-induced cracking is a ubiquitous phenomenon in both natural and artificial materials, including dried sediment layers, paints and glazes on ceramics [Neal et al., 1968; Pollard and Aydin, 1988; Jenkins, 2005; Zhao et al., 2017]. In a dry environment, evaporation of water from soils (particularly, certain soils with high clay content) results in shrinkage of the materials and subsequently generates polygonal crack networks (Figure 1). Polygon-patterned cracks are encountered in a wide variety of scales ranging from a fraction of a millimeter in some drying colloids to several hundreds of meters in playas. Broadly, the morphology of crack networks reflects the drying process and can provide information about ancient climatic conditions. Glennie [1970] observed that desiccation crack patterns can be preserved after their formation if sediment

fills the spaces. Conversely, by understanding the conditions necessary for the formation of desiccation patterns, climatic conditions that prevailed during the history of liquid water activity on earth surface can be estimated. For instance, based on the cracks observed on Mars, El-Maarry et al. [2012, 2013, 2014] made inferences on the paleoclimate of Mars and suggested that liquid water existed on Mars. In addition, surface desiccation cracking patterns are important for quantifying local windblown (aeolian) soil levels [Style et al. 2011]. The appearance of cracks can dramatically increase soil surface roughness. Surface roughness has been shown to reduce the wind speed threshold at which soil particles are picked up from the earth surface.

In engineering works, cracking breaks up the integrity of soils and may lead to various geotechnical and geo-environmental failures. The reduction in the strength of soils due to desiccation cracking may cause failure of exposed earth structures [Morris et al., 1992], landslide [Tang et al., 2011], and mudflow [Wang et al., 2016]. Cracks provide preferential channels for mass transfer which adversely affect the functionality of dams, levees, embankments and landfill barriers [Albrecht and Benson, 2001; Ye et al., 2017]. The presence of cracks increases the weathering depth of soil and aggravates soil erosion on slopes [Tang et al., 2018]. The cracking process also damages plant roots and reduces crop yield [Kelly and Pomes, 1998]. In recent years, 
due to global climate change, droughts occur with an increasing intensity and frequency [Dai, 2011; Pachauri et al., 2014]. A systematic study of soil desiccation cracking behavior is therefore fundamental to evaluate and predict the influence of droughts on earth structures (i.e. dam, embankment and landfill barriers) and ecological systems.

In geological and geoengineering literature, one can find many descriptions of desiccation crack patterns in nature [Weinberger, 1999; Li and Zhang, 2011; Zhang et al., 2017], and in laboratory samples [Groisman and Kaplan, 1994; Yesiller et al., 2000; Rodríguez et al., 2007; Lakshmikantha et al., 2009; Peron et al., 2009; Tang et al., 2011; Costa et al., 2011; Sanchez et al., 2013; Gui et al., 2016; Li et al., 2017; Sun and Cui, 2017; Tollenaar et al., 2017]. However, the dynamics of crack pattern formation and the underlying mechanisms are still unclear. It is commonly postulated that cracking is triggered by tensile stresses that develop due to moisture gradient during desiccation [Corte and Higashi, 1960; Neal et al., 1968; Morris et al., 1992; Jenkins, 2005]. However, up to the present, the spatio-temporal evolution of the tensile stress field in drying soils has not been quantitatively characterized. In past decades, a large number of experiments have been undertaken to determine soil tensile strength through direct and indirect methods [Lu et al., 2009; Venkataramana et al., 2009; Ebrahim-Zadeh et al., 2017]. Most of the tensile tests were performed on compacted soil samples at specific water contents, where the corresponding test conditions are completely different from soil desiccation conditions. More specifically, the measured tensile strength is actually a macro mechanical parameter. It cannot adequately reflect the cracking process that initiate from micro damage, such as the breakage of inter-particle bonding [Shin and Santamarina, 2011]. It is well known that soil is a highly heterogeneous but porous material. The distribution of inter-particle bonding strength or the resistance to tensile failure is not uniform. Currently, there is still not an effective method that can accurately measure the micro-mechanical parameters related to soil tensile failure and its distribution characteristics at particle scale.

The study reported herein, focuses on analyses of the dynamic process of desiccation cracking 
through a continuous full-field strain measurement using digital image correlation. More

.
specifically, the surface of a drying soil was monitored continuously using a digital camera. The evolution of the in-plane strain field during desiccation was obtained and correlated with the observed desiccation cracking patterns. These observations can provide new insights into the initiation and propagation of desiccation cracks in soil. Moreover, the method developed herein, could also be used to investigate the desiccation cracking process in other materials such as paints, plasters and some water-based mixtures.

\section{Material and Experiment method}

\subsection{Material}

The tested material is a clayey soil obtained from Nanjing area, China, at the depth of $0.5-1 \mathrm{~m}$. It is widely deposited in the middle and lower reaches of the Yangtze River and is a very important foundation soil involved in numerous construction projects. Its physical and mechanical properties are summarized in Table 1. Grain size analyses indicate that its sand, silt, and clay contents are $24 \%$, $34 \%$, and $42 \%$, respectively. The mineralogical composition of the clay component was found to be $17.9 \%$ montmorillonite, $73.6 \%$ illite and $8.5 \%$ kaolinite.

\subsection{Experiment method}

The tested material was crushed and sieved to grain sizes smaller than $2 \mathrm{~mm}$. Then, it was mixed with distilled water with a solid/water ratio of $1: 1.7$. The obtained slurry was poured into a glass dish of $117 \mathrm{~mm}$ diameter. The dish was vibrated for 5 min to remove air bubbles and then, covered for at least $72 \mathrm{~h}$ for sedimentation. After that, the pure water above the slurry surface was removed. The sample was finally pruned to $8 \mathrm{~mm}$ thickness, and the measured water content was $115 \%$. Black paint was sprayed on the sample surface to obtain a random speckle pattern for digital image correlation analyses. The speckles, typically sized in of hundreds of micrometers, are sparsely distributed on the sample's surface. Hence, their influence on the characteristics of the 
original soil can be neglected.

The desiccation test was performed under normal laboratory conditions $\left(25 \pm 0.5{ }^{\circ} \mathrm{C}, 50 \pm 3 \%\right.$ relative humidity). The experimental setup is illustrated in Figure 2. A digital camera was fixed above the sample to record images every 30 minutes. The sample was placed on a scale, and the mass loss during drying was monitored. The change in the water content of the sample could then be back-calculated. Several LED lights were placed around the sample to improve the illumination conditions.

The recorded images were analyzed using digital image correlation techniques (DIC). Broadly, DIC entails correlating certain subsets of pixels in the reference image (in position $\underline{X}$ ) with their homologous ones in the deformation image (in position $\underline{x}$ ) [Bornert et al., 2011, Wang et al., 2017]. Once correlation is obtained, the transformation gradient $\left(F_{\mathrm{ij}}=\partial x_{\mathrm{i}} / \partial X_{\mathrm{j}}\right)$ can be assessed approximately by averaging the infinitesimal gradient over a surface, $D$. In practice, the transformation gradient over a surface, $D$ is evaluated from the displacements at its boundary according to Green's theorem [Wang et al., 2015]:

$$
F_{i j}(\underline{X}) \approx \frac{1}{|D|} \int_{D} \frac{\partial x_{i}}{\partial X_{j}} d w=\frac{1}{|D|} \int_{\partial D} x_{i} \otimes n_{j} d s
$$

where $\partial D$ is the boundary of $D$ with outer unit normal $n$. The Green-Lagrange strain $E$ is then calculated:

$$
E=\frac{1}{2}\left(F^{T} \cdot F-I\right)
$$

where ${ }^{T}$ denotes the transpose of a tensor, and $I$ is the second order identity tensor. $D$ can be an assembly of matching subsets with arbitrary shape, and its average deformation can be assessed. When $D$ is delimited by the neighbors of a given matching subset, the local strain is determined (Figure 3). In this work, the DIC analysis and subsequent strain measurements were performed using the CMV software developed at Ecole des Ponts ParisTech, France. The correlation subsets are sized at $40 \times 40$ pixel. The in-plane components of the local strain tensor $\left(\varepsilon_{x x}, \varepsilon_{y y}, \varepsilon_{x y}\right)$ can be evaluated 
at some local gauge length, depending on image characteristics and the chosen DIC parameters. The two in-plane eigenvalues of the 2D Green-Lagrange strain tensor (namely $\varepsilon_{1}$ and $\varepsilon_{2}$ with $\varepsilon_{2}>$

$\left.\varepsilon_{1}\right)$ are then calculated. The convention of continuum mechanics is applied here: tensile strain is positive, while compressive strain is negative. Therefore, $\varepsilon_{2}$ corresponds to the maximum tensile strain or minimum compressive strain (called major strain), while $\varepsilon_{1}$ is the maximum compressive strain (called minor strain). Also, the equivalent strain, $\varepsilon_{\text {eq }}=2\left(\varepsilon_{2}-\varepsilon_{1}\right) / 3$, is assessed as an indicator of shear strain.

(1)

\section{Results and discussion}

\subsection{Desiccation cracking and deformation modes}

The experiments lasted for 5 days. The variation of water content with elapsed time is presented in Figure 4. The water content decreased linearly first, and then reached stabilization gradually. Images were recorded by the camera every 30 minutes, from which 12 images are chosen to show the initiation and propagation of the first 26 cracks (Figure 5). The 26 cracks are numbered according to their order of appearance. The first crack appears at $26.5 \mathrm{~h}$ in the middle of the specimen surface, and the corresponding water content is $66.6 \%$. It subsequently propagates across the specimen, dividing the latter into two parts. Most of the cracks initiate at intact spots instead of from previously existing cracks, but their propagations trend to join adjacent cracks (see for example the onset and propagation of crack 5 in steps 6-8 of Figure 5). One exception is crack 4 which seems to initiate from crack 1. The cracks intersect at right angles forming $\mathrm{T}$ junctions. The explanation of this T-junction pattern is well recognized: the first crack releases the normal stress in its vicinity; the second crack approaches the first orthogonally, that is along the direction perpendicular to the local maximal tensile stress [Weinberger, 1999].

The early-onset cracks such as cracks 1,2,3 and 5 normally show large openings and high lengths, and they are named primary cracks herein. Crack 1 is oriented radially, whereas cracks 2, 3 and 5 are circumferential (sub-parallel to the vessel wall). After the appearance of primary cracks, 
shorter cracks which are considered herein, as being secondary, appear. These secondary cracks typically intersect the primary cracks or earlier secondary cracks at right angles. For instance, crack 6 joins crack 1 and crack 2. Among these secondary cracks, a group of cracks (crack 7, 9-10, 16, 18-21, 24-25) are located between the circumferential primary cracks and the vessel wall.

The $\varepsilon_{1}, \varepsilon_{2}$ and $\varepsilon_{e q}$ strain maps of the specimen surface for the chosen 12 steps are illustrated in Figures 6, 7 and 8, respectively. In these maps, the local strain of a correlation subset is illustrated by a cross: the color indicates the strain magnitude while the major axis indicates the $\varepsilon_{2}$ direction. For better illustration, a zoom of the Figure 7 strain map at step 11 is shown in Figure 9. It is observed that the crack lips involve high tensile strain (in red color) with $\varepsilon_{2}$ direction perpendicular to them, indicating opening of the cracks. However, in the adjacent zone of the cracks, the $\varepsilon_{2}$ strains are negative, indicating compression in the corresponding zone due to the opening of cracks. The compression is even higher (in violet color) at the corner of two intersecting cracks. In addition, a shear-deforming band in which $\varepsilon_{2}$ is oblique to the orientation of the band (see the yellow band in Figure 9), is observed.

From the above discussion, the $\varepsilon_{2}$ direction can serve as an indicator of the crack mode. For instance, $\varepsilon_{2}$ is perpendicular to the opening of a I-mode crack (i.e., tensile crack) whereas $\varepsilon_{2}$ is oblique to the opening of a II-mode crack (i.e., shear crack). Examining the 26 cracks in our experiment, all of them are in I-mode. It should be noted that the cracks propagate not only laterally in the free surface but also vertically inside the sample. Nevertheless, the present $2 \mathrm{D}$ measurements focus on the crack patterns of the free surface. Information on deeper-seated geometries is not available.

\subsection{Precursor of desiccation cracking}

Shrinking is heterogeneous within the sample, even before the appearance of cracks (see step 1 of Figure 6). A red (compaction) ring is observed at the specimen edge. Considering its form, this shrinkage ring should be caused by the external restraint provided by the vessel wall. Interestingly, 
tensile strains appear during the shrinking process (see the yellow and red colors in step 1 of Figure 7). In particular, the $\varepsilon_{2}$ map at step 1 is characterized by a red ring, as well as four red points which involve high tensile strains. The tensile-straining ring appears at the immediate inner side of the compaction ring. Thus, the two rings are compatible and should derive from the same mechanism. In the subsequent steps, cracks 2 and 3 initiate from this high-tensile-straining ring. Crack 3 is a good example of the key role played by the high-tensile-straining ring in the observed cracking phenomena. The corresponding domain in crack 3 has already suffered from high tensile straining in step 1 and is cracked at step 5. Then, crack 3 propagates, following exactly the path of the ring before deviating towards crack 2 (see steps 5-7 in Figure 7). Crack 5 does not initiate from the high-tensile-straining ring. Nevertheless, when it approaches the ring, it subsequently propagates along the ring's path.

In addition to the high-tensile-straining ring, four isolated points involving pronounced tensile deformation, are also found before the onset of cracking. They are designated as A-D in step 1 of Figure 7. These points arise from the flaws of the material (e.g., inclusions, pores, grain boundaries). It is found that point A gives rise to the initiation of crack 1 at step 2, while point D leads to the onset of crack 6 at step 7. For the other two points, point B disappears at step 2, because the opening of crack 1 releases the normal stress at its vicinity; similarly, cracks 4 and 6 relieve the high-straining of point $\mathrm{C}$ (see steps 6-7 in Figure 7).

To examine whether desiccation cracking might arise in mode II, the $\varepsilon_{\text {eq }}$ maps are shown in Figure 8. Compared to those found in $\varepsilon_{1}$ and $\varepsilon_{2}$ maps, no more high-straining zones are found in $\varepsilon_{\text {eq }}$ maps. Two high $\varepsilon_{\mathrm{eq}}$ rings are found at the boundary of the specimen: the outer one mainly arises from high compaction, and the inner one results from high tensile straining. The outer high $\varepsilon_{\text {eq }}$ ring might explain the initiation of the outer radial cracks near the vessel wall, exemplified by cracks 7,18 and 25. To examine this, the evolution of the strains in the domain of crack 7 (see the definition of the domain at reference stage of Figure 6) is shown in Figure 10. It is found that before the initiation of the crack at step 7, the $\varepsilon_{\text {eq }}$ of the domain increases gently until reaching $1.5 \%$ at step $6(29.5 \mathrm{~h})$. 
1 Considering that the $\varepsilon_{\text {eq }}$ in the domain of crack 4 attains $7.4 \%$ without crack initiation, the shear in the domain of crack 7 is too small to activate the cracking. Hence, the strain at the surface cannot provide precursory information on the initiation of crack 7; the latter probably initiates inside the specimen and propagates to the free surface afterwards.

In summary, the strain maps before the onset of cracking already contain precursory information on the cracking phenomenon that would subsequently occur (the early generation of cracks particularly) in mode I. The high tensile straining stems from either the external restraint or from the flaws of the shrinking material.

\subsection{Propagation of desiccation cracks}

Desiccation cracks that are observed in this study do not always propagate along a straight path but are curved such as cracks $2,3,5,6,11$ and 17. As discussed previously, the curved cracks 2, 3, 5, 11 and 17 are related to the high-tensile-straining ring. In addition, the curved propagation is also affected by the existence of adjacent cracks: when a new crack propagates toward an early-generated crack, the former seems to be "attracted" by the latter, and the two finally join orthogonally. Crack 6 is a good illustration of this phenomenon. The initial propagation path of this crack is perpendicular to crack 1 (at step 7). However, when approaching crack 2, the crack deviates from the initial path and finally intersects crack 2 at right angles (at step 8). To gain some insights into the mechanism of this deviating path, the $\varepsilon_{2}$ strain field around crack 6 at steps $6-8$, are zoomed (see the definition of the zoomed zone in step 8 of Figure 7) and shown in Figure 11. Before the arrival of crack 2, the $\varepsilon_{2}$ directions in the zone of crack 6 are rather randomly distributed. However, these $\varepsilon_{2}$ directions are redistributed when crack 2 passes through: the $\varepsilon_{2}$ directions in the crack lips are perpendicular to the length of crack 2, whereas they are parallel to the length in the vicinity. These redistributed $\varepsilon_{2}$ directions define the propagation path of crack 6 deviating towards crack 2 at right angles, because the crack should propagate along the direction perpendicular to the major tensile stress (consistent with the $\varepsilon_{2}$ direction). 
Only a small fraction of cracks (i.e., cracks $1,2,3,6)$ seems to be linked with the strain field measured at the sample surface. To confirm this quantitatively, the evolution of the strains in the initiation domains of cracks 4 and 17 are given in Figure 10. The definitions of the two domains are shown in Figure 6, and their strains are calculated from the displacements of their boundaries using Equation 1).

From Figure 10, the strains in the two domains do not always change monotonously with time. This is mainly because the onset of neighboring cracks would lead to stress release. Regarding crack 4, the tensile strain at its initiation domain already reaches $10.3 \%$ at step 1 without cracking (see Figure 10a). Because of the opening of crack 1, the strain even falls to negative $(-0.2 \%)$ at step 4, prior to crack initiation at step 5. The tensile strain is $13.6 \%$ when crack 4 appears. Thus, it is deduced that the tensile strain threshold for that cracking is between $10.3 \%$ and $13.6 \%$. Crack 17 appears inside the high-tensile-straining ring. Nevertheless, the evolution of strain at its initiation domain shows that, before the initiation at step 10, the maximum tensile strain appears at step 5 (5.9\%) instead of step $9(5.7 \%)$. The two declining portions at steps 6 and 8 stem from the stress releases induced by the initiation of crack 5 and 9 , respectively.

From the analysis above, it can be inferred that a significant portion of desiccation cracks might initiate at depth and propagate upwards to the surface. This is contradictory to the prevailing claim that such cracks initiate from the surface and propagate downwards because the tensile stress due to self-restraint is maximal at the surface [Jenkins, 2005]. Actually, in addition to the self-restraint effect, the heterogeneous strain fields suggest that material heterogeneity also plays a key role in cracking process.

When desiccation proceeds, the drying surface penetrates inside the specimen and may encounter heterogeneous points such as flaws. The resulting concentrated stress due to strain incompatibility could give rise to cracking at depth. Moreover, when the drying front reaches the vessel bottom, the restraint of the vessel bottom on the shrinking of the material also results in 
tensile stresses that eventually cause cracking. The cracks nucleate at the bottom then propagate upwards. This kind of cracking mechanism is confirmed by the picture shown in Figure 12. Base on the discussions above, we suggest that, although evaporation of water begins at the exposed surface, desiccation cracks can nucleate inside the sample and propagate upwards.

\section{Conclusions}

The initiation and propagation of polygonal desiccation cracks in soil were investigated through full-field strain measurements on the desiccation surface. It is found that desiccation cracking can be reliably predicted by the full-field strain analysis of surfaces because they already exhibit high-stretching before the appearance of cracks. The high stretching stems from either external restraint or internal flaws of the shrinking soil. Desiccation cracks do not always propagate in straight lines. Some of the curved cracks are controlled by the prevailing boundary conditions (e.g., the circle-shaped restraint from the vessel in this work). Other controlling factors are related to the stress redistribution of the neighboring cracks, which requires the cracks to intersect each other orthogonally. The final geometrical characteristics of crack pattern are actually determined by the interactions between cracking development and stress redistribution. Although drying begins from the exposed surface, cracks (particularly the ones generated later) could nucleate in the subsurface, and propagate upwards to the surface.

\section{Acknowledgments}

The authors would like to acknowledge Dr. Michel Bornert at Ecole des Ponts ParisTech for using CMV software for digital image correlation analyses. This work was supported by the Science Foundations of China University of Petroleum, Beijing (Grant No.2462016YJRC021, No.2462018BJC002), National Natural Science Foundation of China (Grant No. 41572246, 41772280, 41322019), Natural Science Foundation of Jiangsu Province (BK20171228, BK20170394), Key Project of National Natural Science Foundation of China (Grant No. 
41230636), and the Fundamental Research Funds for the Central Universities.

\section{References}

Albrecht, B.A., Benson, C.H., 2001. Eff ect of desiccation on compacted natural clays. Journal of Geotechnical and Geoenvironmental Engineering. 127, 67-75.

Bornert, M., Orteu, J.J., Roux, S., 2011. Corrélation d'images. Hermès Science. Chapter 6, $175-208$.

Corte, A., Higashi, A., 1960. Experimental research on desiccation cracks in soil-Research Report 66. Research Report U.S. Army Snow Ice and Permafrost Research Estabilishment, Wilmette, Illinois.

Costa, S., Kodikara, J., Shannon, B., 2012. Salient factors controlling desiccation cracking of clay in laboratory experiments. Géotechnique, 63(1), 18-29.

Dai, A., 2011. Drought under global warming: a review. Wiley Interdisciplinary Reviews: Climate Change, 2(1), 45-65.

Ebrahim-Zadeh, G., Bayat, H., Sinegani, A.A.S., Abyaneh, H.Z., Vereecken, H., 2017. Investigating the correlation between soil tensile strength curve and soil water retention curve via modeling. Soil and Tillage Research. 167, 9-29.

El-Maarry, M.R., Kodikara, J., Wijessoriya, S., Markiewicz, W.J., Thomas, N., 2012. Desiccation mechanism for formation of giant polygons on Earth and intermediate-sized polygons on Mars: Results from a pre-fracture model. Earth and Planetary Science Letters. 323, 19-26.

El-Maarry, M.R., Pommerol, A., Thomas, N., 2013. Analysis of polygonal cracking patterns in chloride bearing terrains on Mars: Indicators of ancient playa settings. Journal of Geophysical Research: Planets. 118(11), 2263-2278.

El-Maarry, M.R., Watters, W., McKeown, N.K., Carter, J., Dobrea, E.N., Bishop, J.L., Pommerol, A., Thomas, N., 2014. Potential desiccation cracks on Mars: A synthesis from modeling, analogue-field studies, and global observations. Icarus. 241, 248-268.

Glennie, K.W., 1970. Wadis and desert fluviatile soils. In Desert Soilary Environments. Elsevier, 
Amsterdam, 29-56.

Groisman, A., Kaplan, E., 1994. An experimental study of cracking induced by desiccation. Europhysics Letters. 25, 415-420.

Gui, Y.L., Zhao, Z.Y., Kodikara, J., Bui, H.H., Yang, S.Q., 2016. Numerical modelling of laboratory soil desiccation cracking using UDEC with a mix-mode cohesive fracture model. Engineering Geology. 202, 14-23.

Jenkins, D.R., 2005. Optimal spacing and penetration of cracks in a shrinking slab. Physical Review E. 71, 056117.

Kelly, B.P., Pomes, M.L., 1998. Preferential flow and transport of nitrate and bromide in a clay pan soil. Ground Water. 36, 484-494.

Lakshmikantha, M.R., Prat, P.C., Ledesma, A., 2009. Image analysis for the quantification of a developing crack network on a drying Soil. Geotechnical Testing Journal. 32(6), 505-515.

Li, J.H., Lu, Z., Guo, L.B., Zhang, L.M., 2017. Experimental study on soil-water characteristic curve for silty clay with desiccation cracks. Engineering Geology. 218(23), 70-76.

Li, J.H., Zhang, L.M., 2011. Study of desiccation crack initiation and development at ground surface. Engineering Geology. 123(4), 347-358.

Lu, N., Kim, T.H., Sture, S., Likos, W.J., 2009. Tensile strength of unsaturated sand. Journal of Engineering Mechanics. 135(12), 1410-1419.

Morris, P.H., Graham, J., Williams, D.J., 1992. Cracking in drying soils. Canadian Geotechnical Journal. 29(2), 263-277.

Neal, J.T., Langer, A.M., Kerr, P.F., 1968. Giant desiccation polygons of Great Basin playas. Geological Society of America Bulletin. 79, 69-90.

Pachauri, R.K., Allen, M.R., Barros, V.R., Broome, J., Cramer, W., Christ, R., Church, J.A., Clarke, L., Dahe, Q., Dasgupta, P., Dubash, N.K., 2014. Climate change 2014: synthesis report. Contribution of Working Groups I, II and III to the fifth assessment report of the Intergovernmental Panel on Climate Change. IPCC. 
Peron, H., Hueckel, T., Laloui, L., Hu, L.B., 2009. Fundamentals of desiccation cracking of fine grained soils: experimental characterisation and mechanisms identification. Canadian Geotechnical Journal. 46, 1177-1201.

Pollard, D.D., Aydin, A., 1988. Progress in understanding jointing over the past century. Geological Society of America Bulletin. 100, 1181-1204.

Rodríguez, R., Sánchez, M., Ledesma, A., Lloret, A., 2007. Experimental and numerical analysis of desiccation of a mining waste. Canadian Geotechnical Journal. 44, 644-658.

Sanchez, M., Atique, A., Kim, S., Romero, E., Zielinski, M., 2013. Exploring desiccation cracks in soils using a 2D profile laser device. Acta Geotechnica. 8(6), 583-596.

Shin, H., Santamarina, J.C., 2011. Desiccation cracks in saturated fine-grained soils: particle level phenomena and effective stress analysis. Géotechnique. 61(11), 961-972.

Style, R.W., Peppin, S.S., Cocks, A.C., 2011. Mud peeling and horizontal crack formation in drying clays. Journal of Geophysical Research: Earth Surface. 116(F1).

Sun, W.J. and Cui, Y.J., 2017. Investigating the microstructure changes for silty soil during drying. Géotechnique, 1-4.

Tang, C.S., Shi, B., Liu, C., Suo, W.B., Gao, L., 2011. Experimental characterization of shrinkage and desiccation cracking in thin clay layer. Applied Clay Science. 52, 69-77.

Tang, C.S., Wang, D.Y., Zhu, C., Zhou, Q.Y., Xu, S.K. and Shi, B., 2018. Characterizing drying-induced clayey soil desiccation cracking process using electrical resistivity method. Applied Clay Science. 152, 101-112.

Tollenaar, R.N., van Paassen, L.A., Jommi, C., 2017. Observations on the desiccation and cracking of clay layers. Engineering Geology. 230(29), 23-31.

Venkataramana, K., Rao, B.H., Singh, D.N., 2009. A critical review of the methodologies employed for determination of tensile strength of fine-grained soils. Journal of Testing and Evaluation. 37(2), $115-121$.

Wang, L.L., Bornert, M., H’eripr'e, E., Chanchole, S., Pouya, A., Halphen. B., 2015. Microscale insight 
into the influence of humidity on the mechanical behavior of mudstones. Journal of Geophysical Research: Solid Earth. 120 (15), 3173-3186.

Wang, L.L., Zhang, G.Q., Hallais, S., Tanguy, A., Yang, D.S., 2017. Swelling of shales: a multiscale experimental investigation. Energy \& Fuel. 31(10), 10442-10451.

Wang, D.Y., Tang, C.S., Cui, Y.C., Shi, B., Li, J., 2016. Effects of wetting drying cycles on soil strength profile of a silty clay in micro-penetrometer tests. Engineering Geology. 206, 60-70.

Weinberger, R., 1999. Initiation and growth of cracks during desiccation of stratified muddy soils. Journal of Structure Geology. 21, 379-386.

Yesiller, N., Miller, C.J., Inci, G., Yaldo, K., 2000. Desiccation and cracking behavior of three compacted landfill liner soils. Engineering Geology. 57, 105-121.

Ye, W.M., Xu, L., Ye, B., Chen, B., Chen, Y.G., Cui, Y.J., 2017. Experimental investigation on gas migration in saturated Shanghai soft clay. Engineering Geology. 222, 20-28.

Zhang, Y., Ye, W.M., Chen, B., Chen, Y.G., Ye, B., 2016. Desiccation of NaCl-contaminated soil of earthen heritages in the Site of Yar City, northwest China. Applied Clay Sciences. 124,1-10.

Zhang, Y., Ye, W.M., Chen, Y.G., Chen, B., 2017. Impact of $\mathrm{NaCl}$ on drying shrinkage behavior of low plastic soil in earthen heritages. Canadian Geotechnical Journal. 54(12), 1762-1774.

Zhao, B., Zhang, G.Q., Zhao, P.Y., Wang, L.L., Lin, Y., Lv, Y.J., 2017. Experimental study of mechani cs and seepage characteristics of sandstones after liquid-nitrogen stimulation. Journal of Natural G as Science and Engineering, 47, 11-21. 


\section{Tables}

2

3 Table 1. Physical and mechanical properties of the tested soil.

\begin{tabular}{lc}
\hline Soil properties & Value \\
\hline Specific gravity $\left(\mathrm{g} / \mathrm{cm}^{3}\right)$ & 2.71 \\
Consistency limit & 76.2 \\
$\quad$ Liquid limit (\%) & 29.1 \\
$\quad$ Plastic limit (\%) & 47.1 \\
$\quad$ Plasticity index (\%) & $\mathrm{CH}$ \\
USCS classification & \\
Compaction study & 18.3 \\
Optimum moisture content (\%) & 1.69 \\
Maximum dry density $\left(\mathrm{g} / \mathrm{cm}^{3}\right)$ & \\
Particle size analysis & 24 \\
Sand (\%) & 34 \\
Silt (\%) & 42 \\
Clay (\%) & 4 \\
\hline
\end{tabular}




\section{Figure captions}

2 Figure 1. Desiccation crack polygon in natural soil.

3 Figure 2. Schema of experimental setup.

4 Figure 3. Implementation of DIC analysis. The correlation subset is in size of $40 \times 40$ pixel, and its

5 local strain is calculated from the displacements of the eight closest neighbors using Equation 1).

$6 \quad$ Figure 4. Change of water content with elapsed time during drying.

7 Figure 5. Evolution of crack patterns on the specimen surface.

8 Figure 6. $\varepsilon_{1}$ (most compressive strain) maps of the specimen surface at different desiccation

9 moment. The convention is: tensile strain is positive, while compressive strain negative.

10 Figure 7. $\varepsilon_{2}$ (most tensile strain) maps of the specimen surface at different desiccation moment. The 11 convention is: tensile strain is positive, while compressive strain negative.

12 Figure 8. $\varepsilon_{e q}$ (shear strain) maps of the specimen surface at different desiccation moment. The 13 convention is: tensile strain is positive, while compressive strain negative.

14 Figure 9. A zoomed domain of $\varepsilon_{2}$ map at step 11. The local strain of a correlation subset is

15 illustrated by a cross: the color indicates the strain magnitude, while the major axis indicates the $\varepsilon_{2}$ 16 direction.

17 Figure 10. Strain history of the domains of interest: a) $\varepsilon_{2}$, b) $\varepsilon_{\text {eq }}$. The three domains are defined in $18 \quad$ Figure 6.

19 Figure 11. Deviated propagation of crack towards the adjacent crack.

20 Figure 12. A crack nucleated at the bottom of the sample and propagated upwards. 


\section{$1 \quad$ Figures}

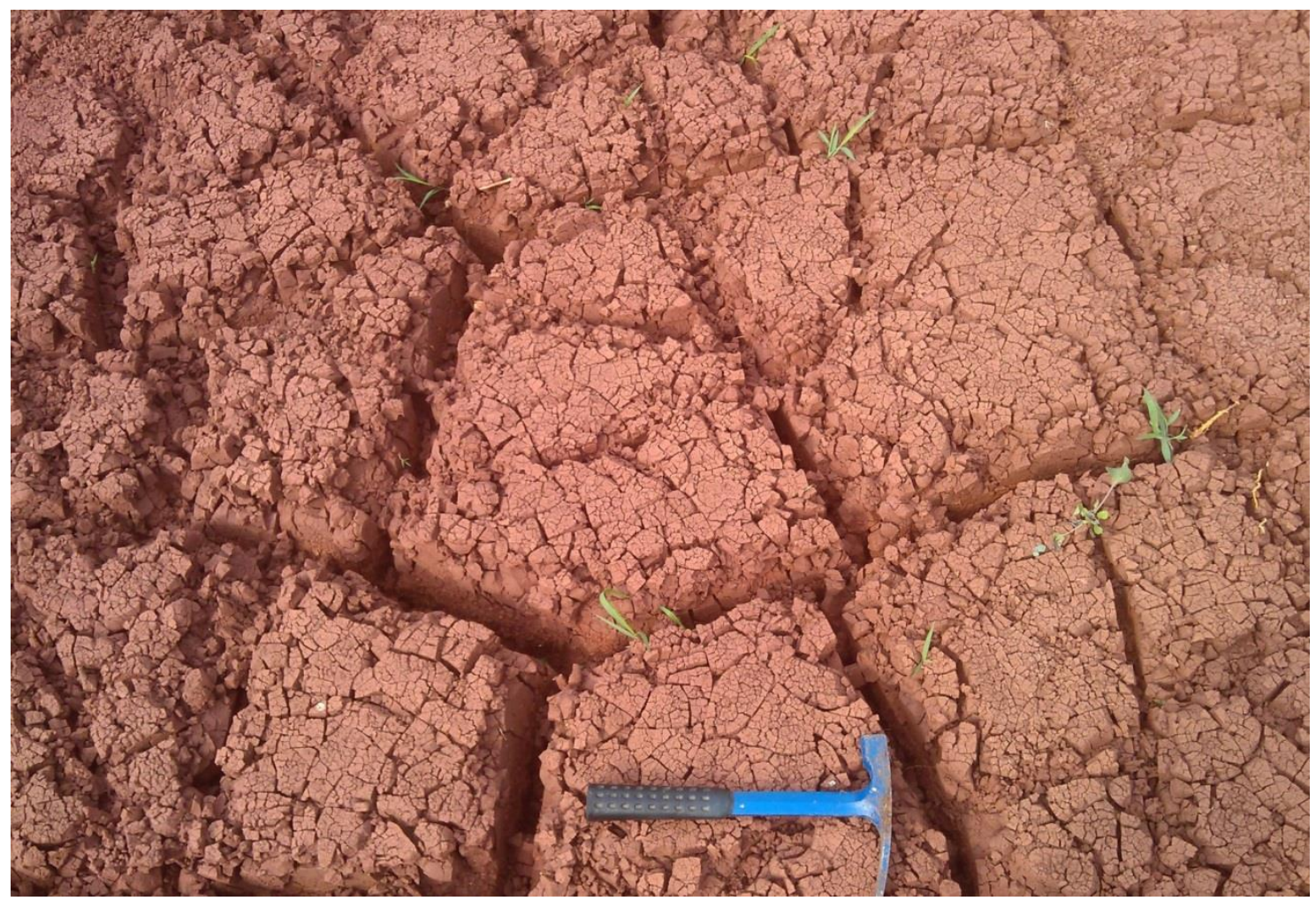

Figure 1. Desiccation crack polygon in natural soil. 
3

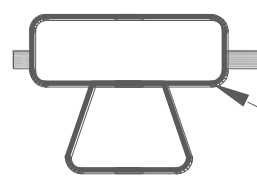

\section{Camera}

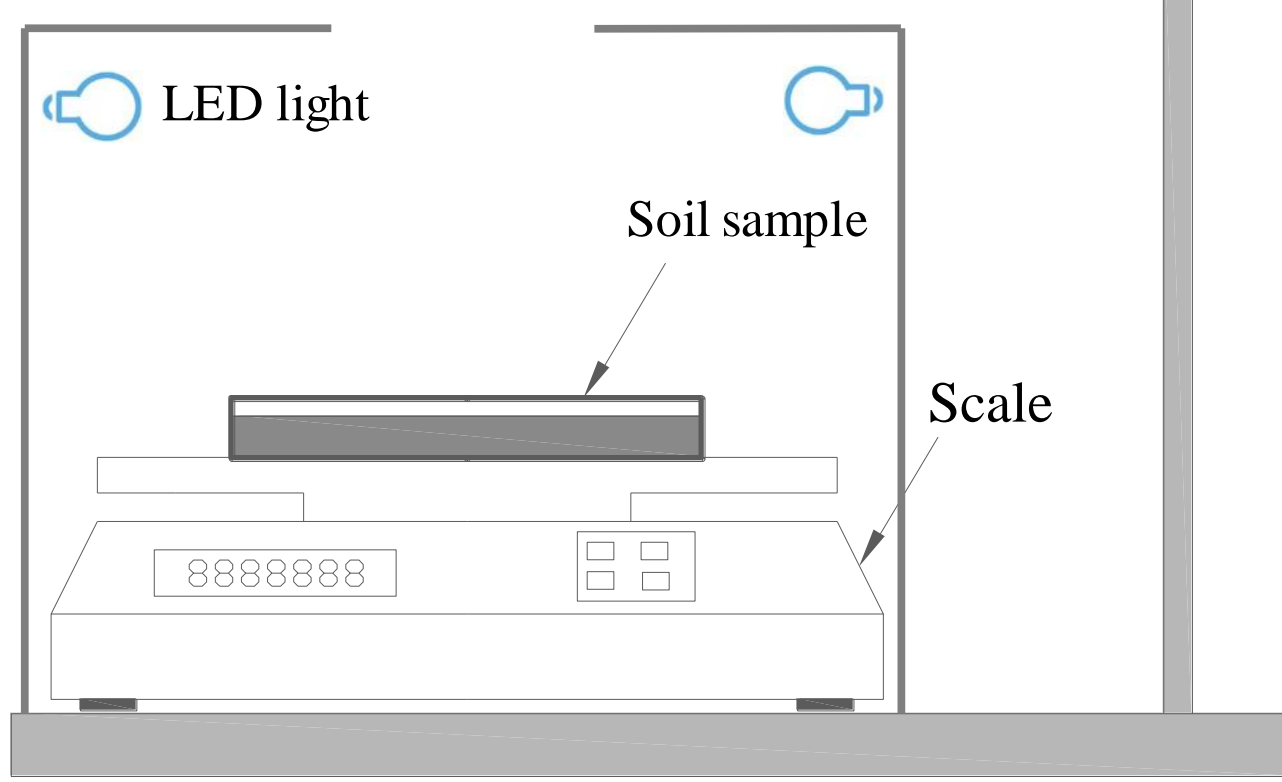

Figure 2. Schema of experimental setup. 


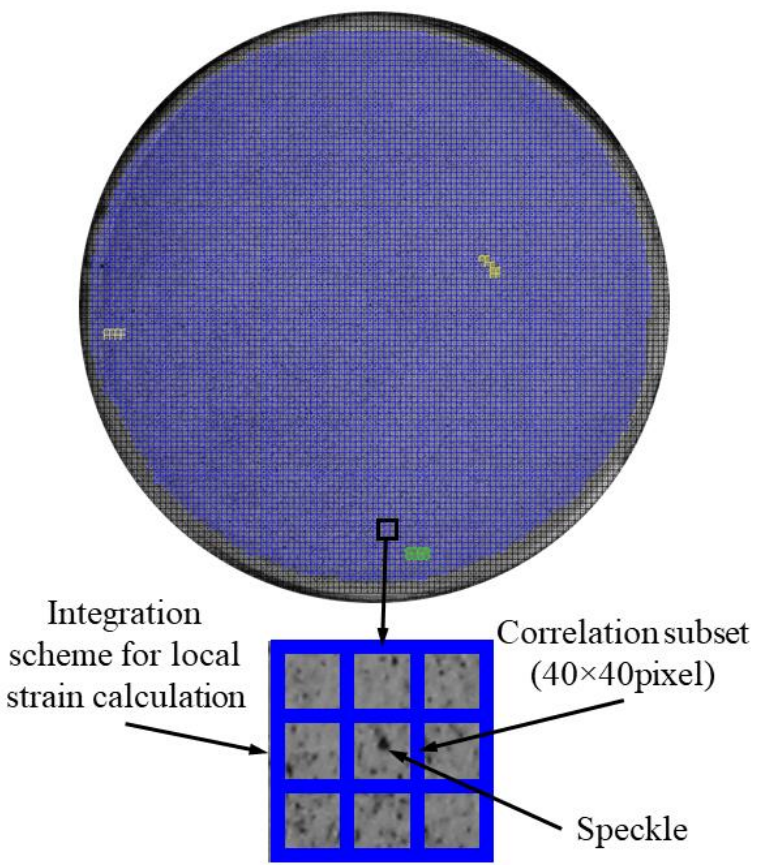

4 Figure 3. Implementation of DIC analysis. The correlation subset is in size of $40 \times 40$ pixel, and its

5 local strain is calculated from the displacements of the eight closest neighbors using Equation 1). 


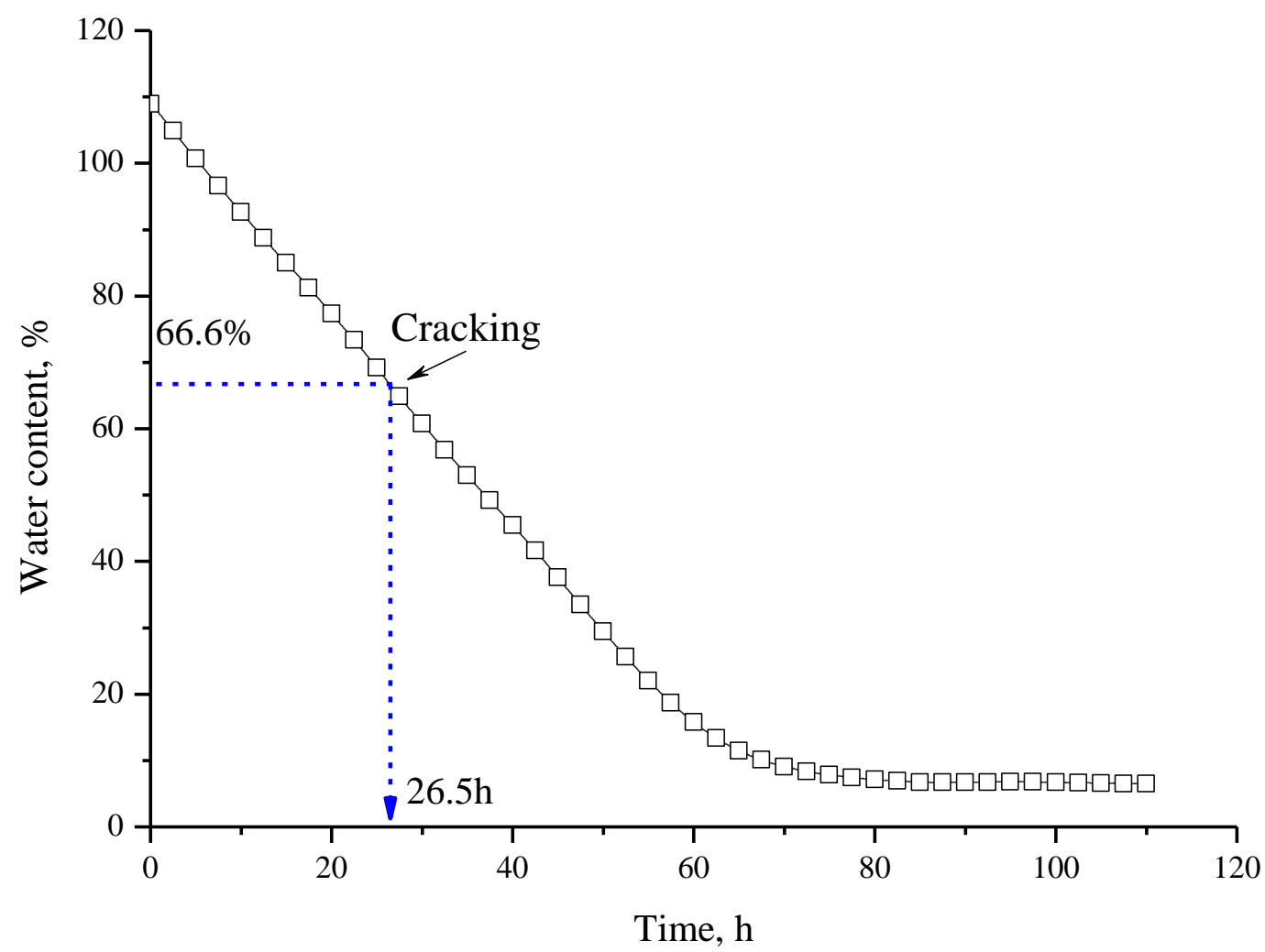

Figure 4. Change of water content with elapsed time during drying. 

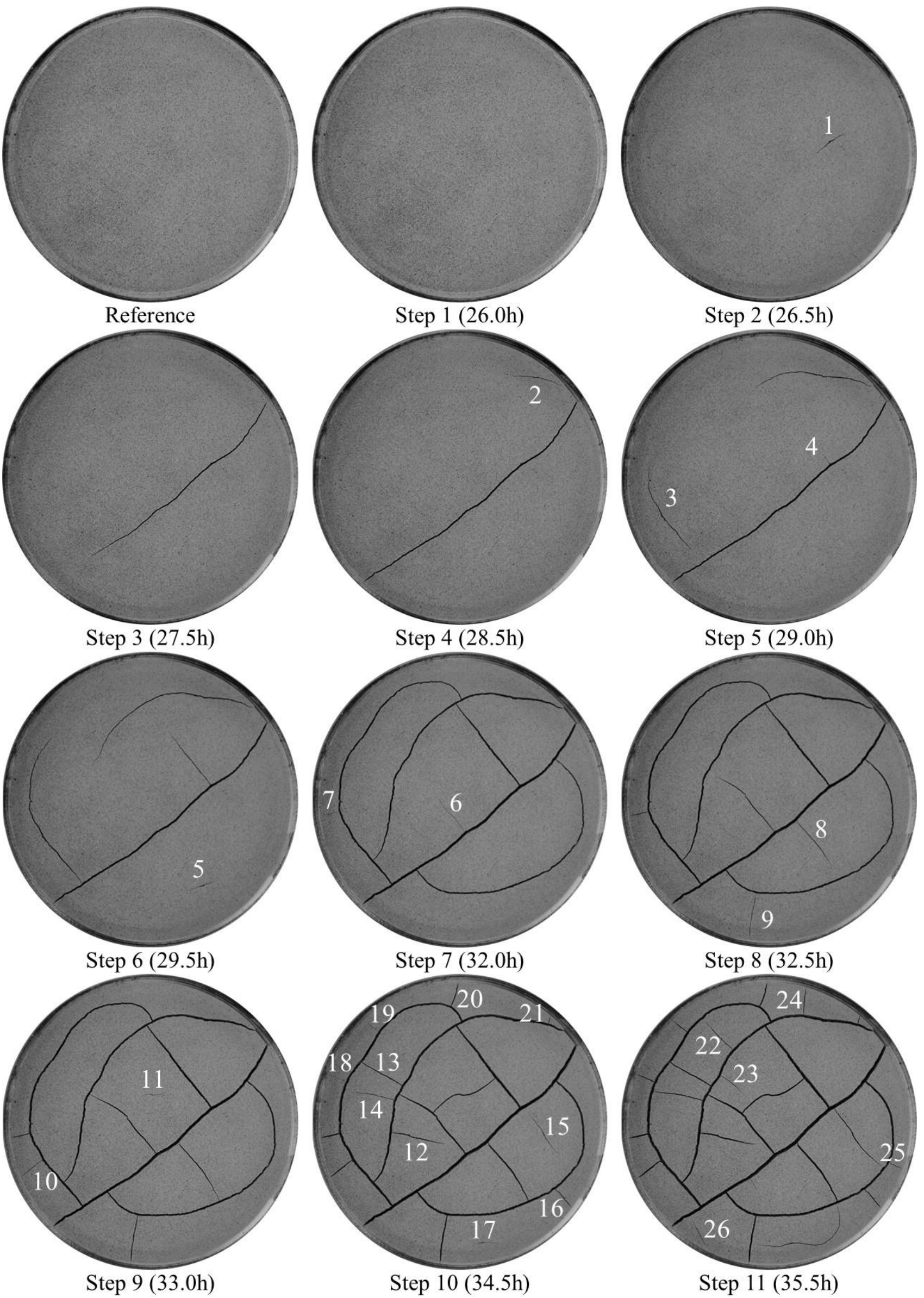

Figure 5. Evolution of crack patterns on the specimen surface. 

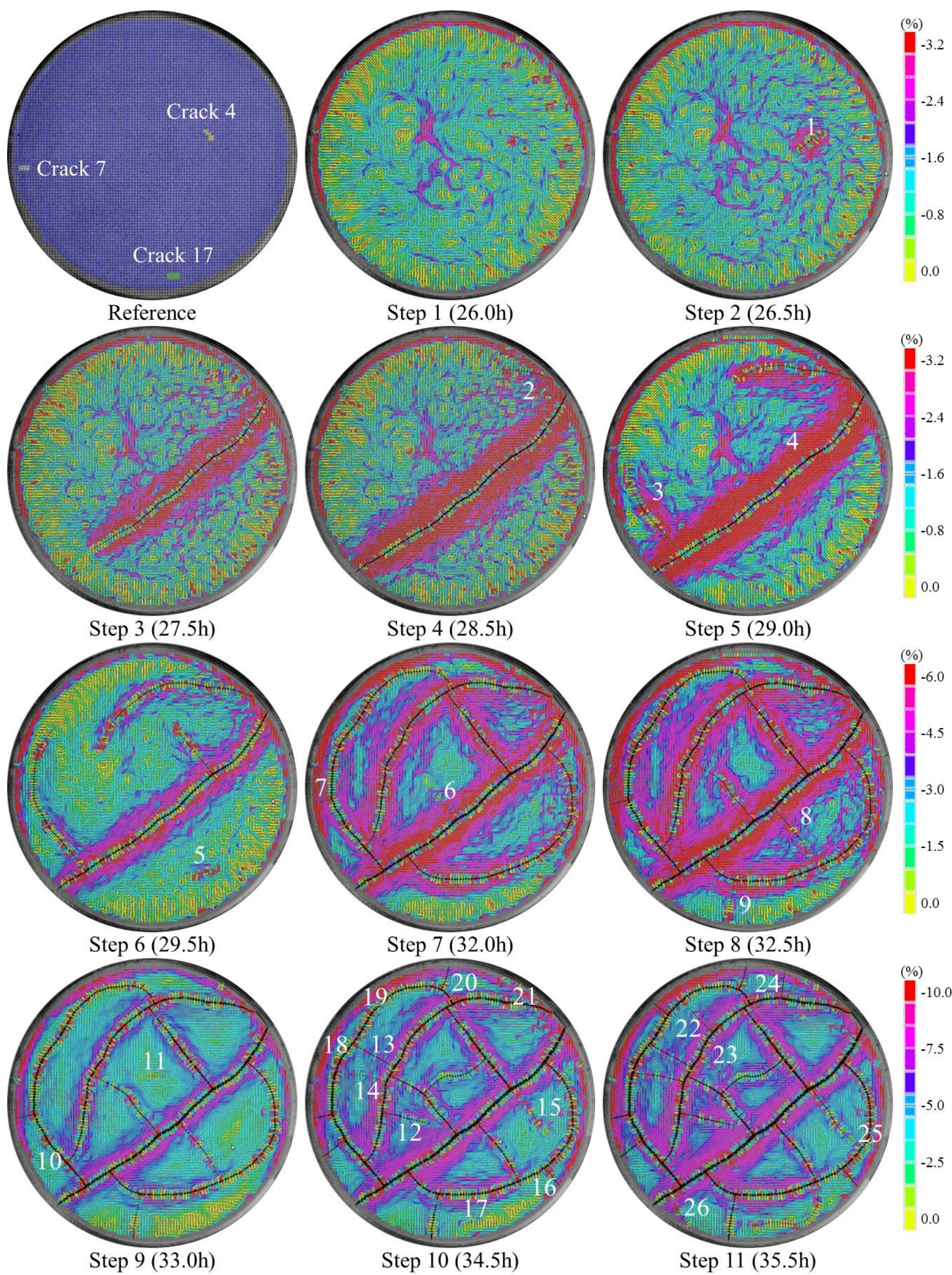

Figure 6. $\varepsilon_{1}$ (most compressive strain) maps of the specimen surface at different desiccation moment. The convention is: tensile strain is positive, while compressive strain negative. 

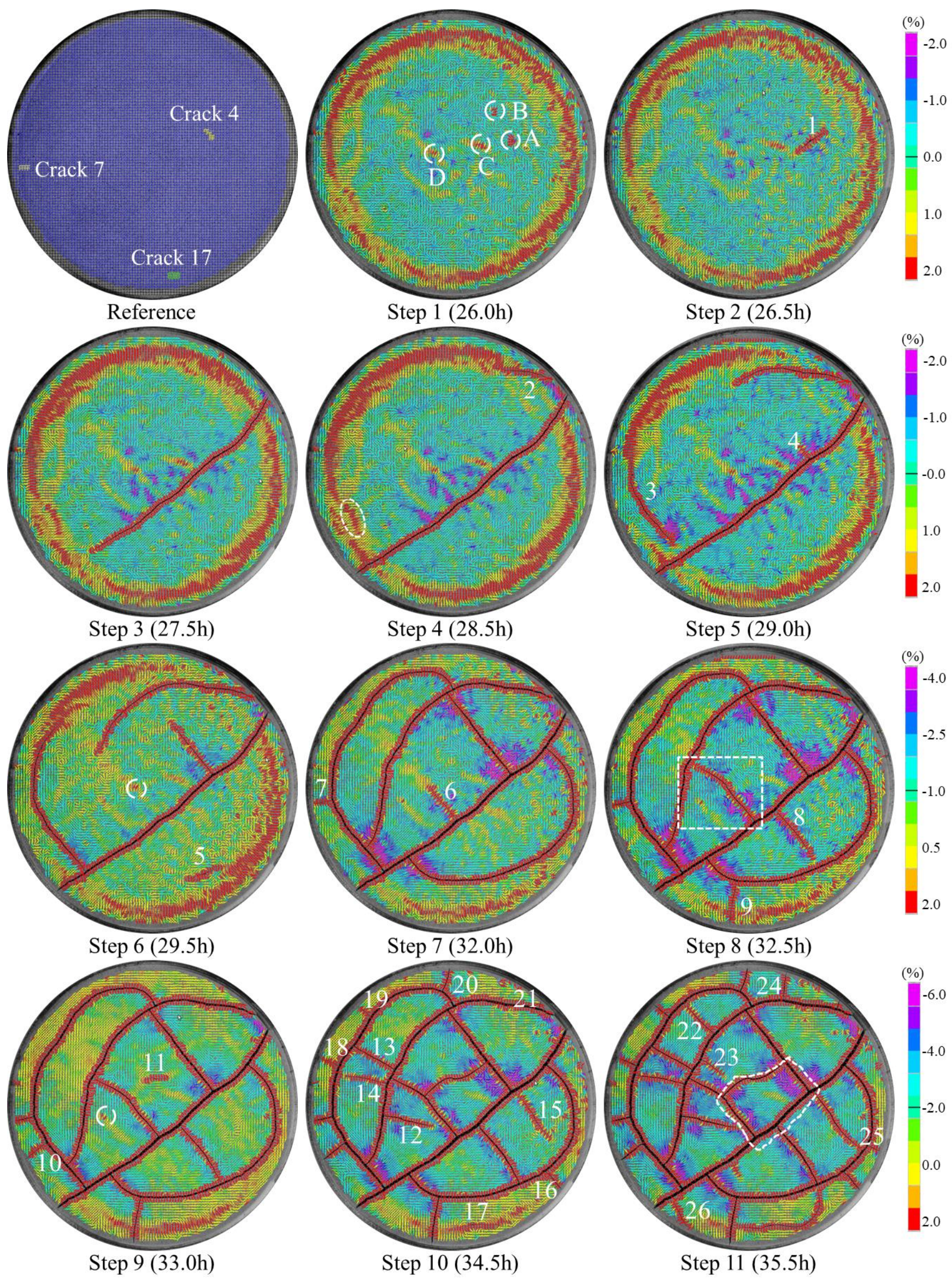

Figure 7. $\varepsilon_{2}$ (most tensile strain) maps of the specimen surface at different desiccation moment.

The convention is: tensile strain is positive, while compressive strain negative. 

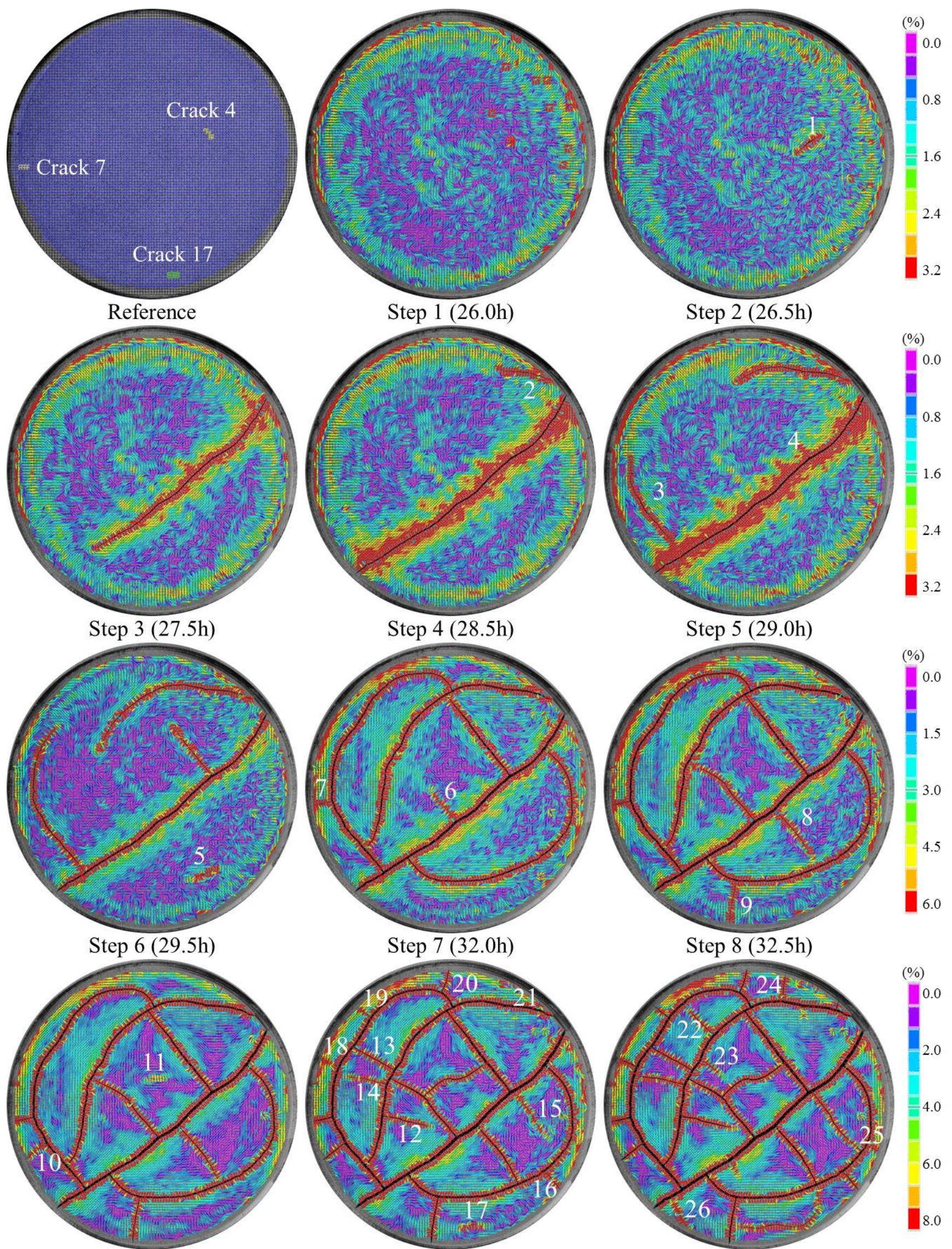

Step $10(34.5 \mathrm{~h})$

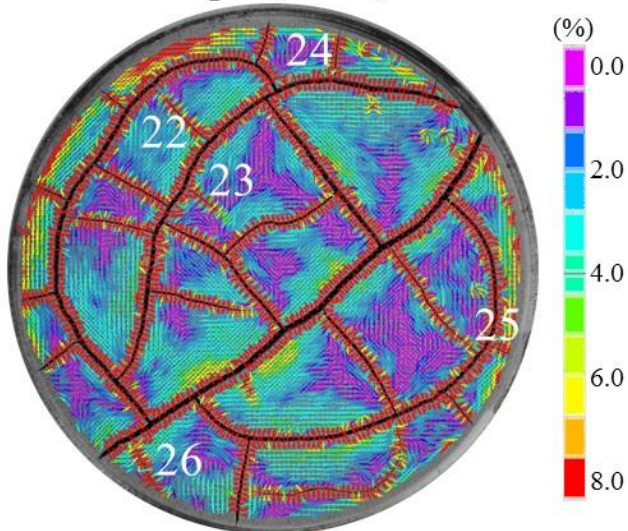

Step $11(35.5 \mathrm{~h})$

Figure 8. $\varepsilon_{e q}$ (shear strain) maps of the specimen surface at different desiccation moment. The convention is: tensile strain is positive, while compressive strain negative. 


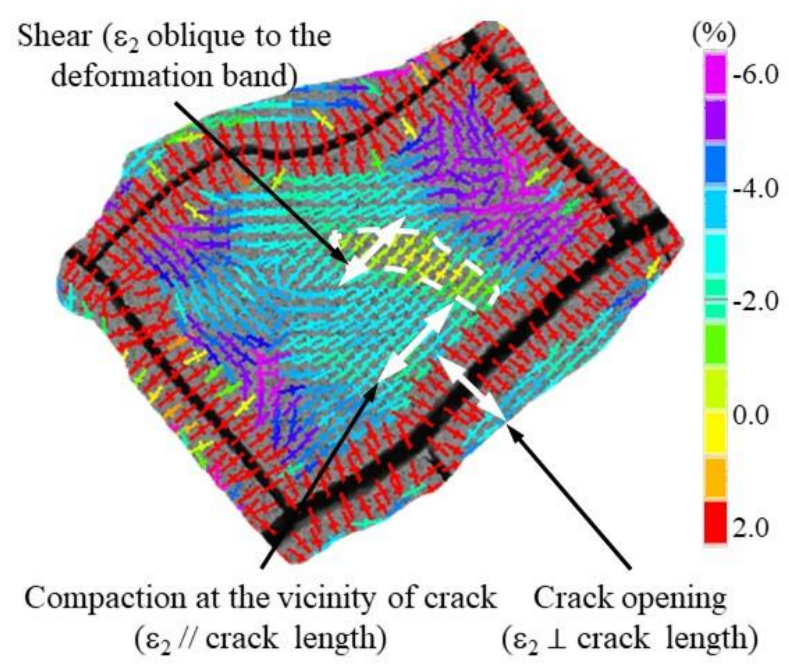

2 Figure 9. A zoomed domain of $\varepsilon_{2}$ map at step 11. The local strain of a correlation subset is

3 illustrated by a cross: the color indicates the strain magnitude, while the major axis indicates the $\varepsilon_{2}$ 4 direction. 

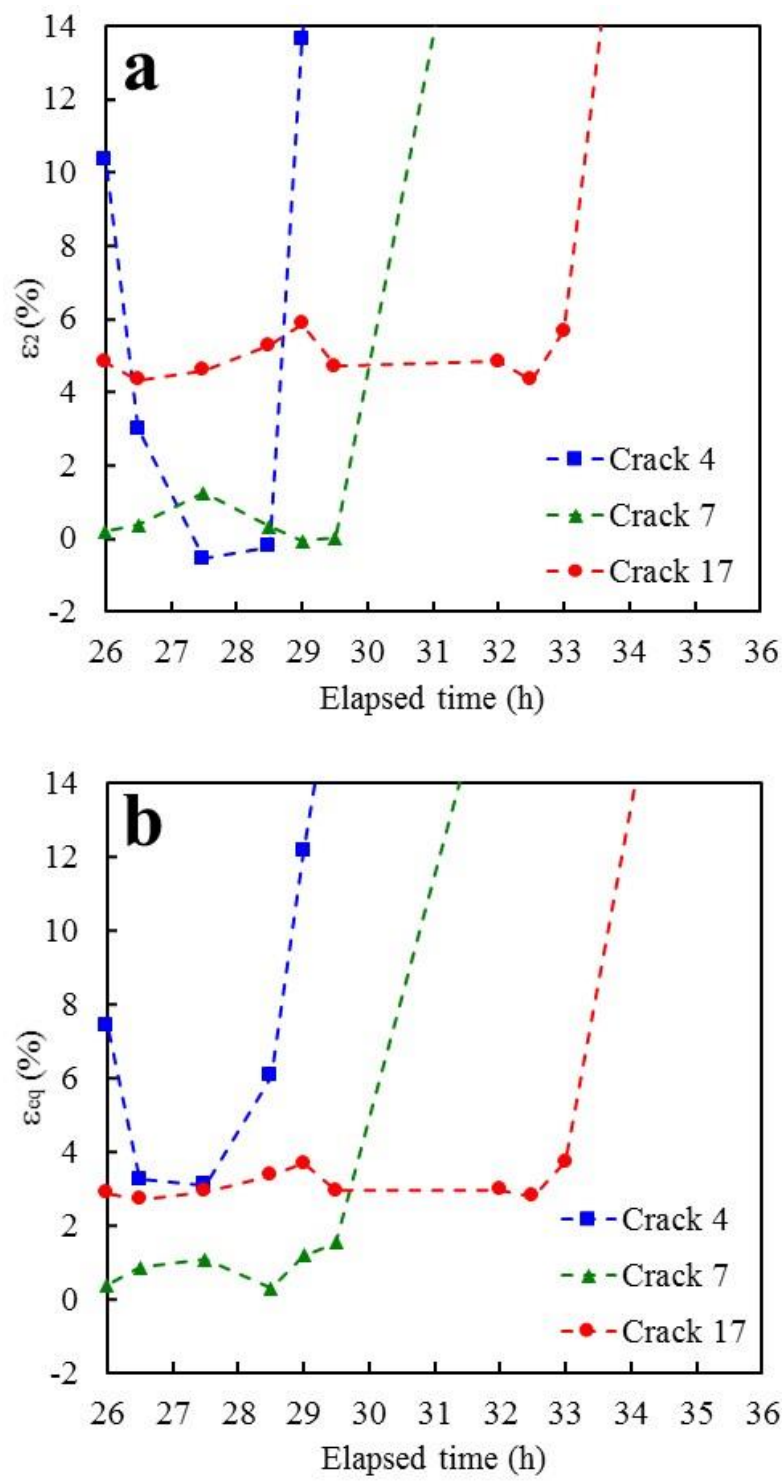

3

Figure 10. Strain history of the domains of interest: a) $\varepsilon_{2}$, b) $\varepsilon_{\mathrm{eq}}$. The three domains are defined in Figure 6. 
Initial unordered dis tribution of $\varepsilon_{2}$ direction

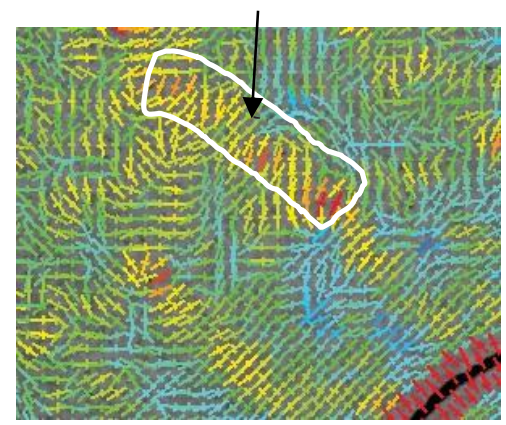

Step 6
Ordered redistribution of $\varepsilon_{2}$ direction due to cracking ( $\varepsilon_{2} / /$ crack length)

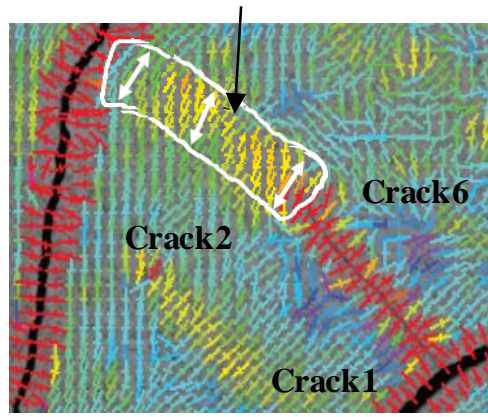

Step 7

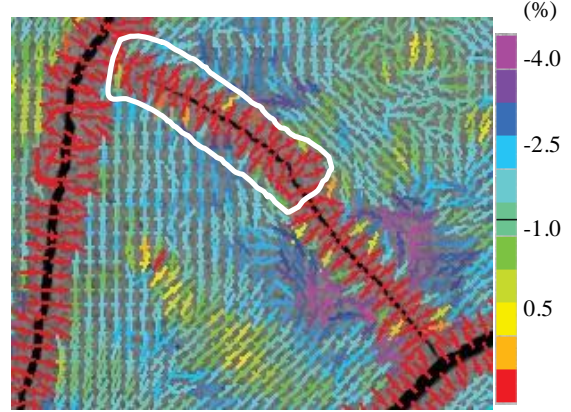

Step 8

2

Figure 11. Deviated propagation of crack towards the adjacent crack. 


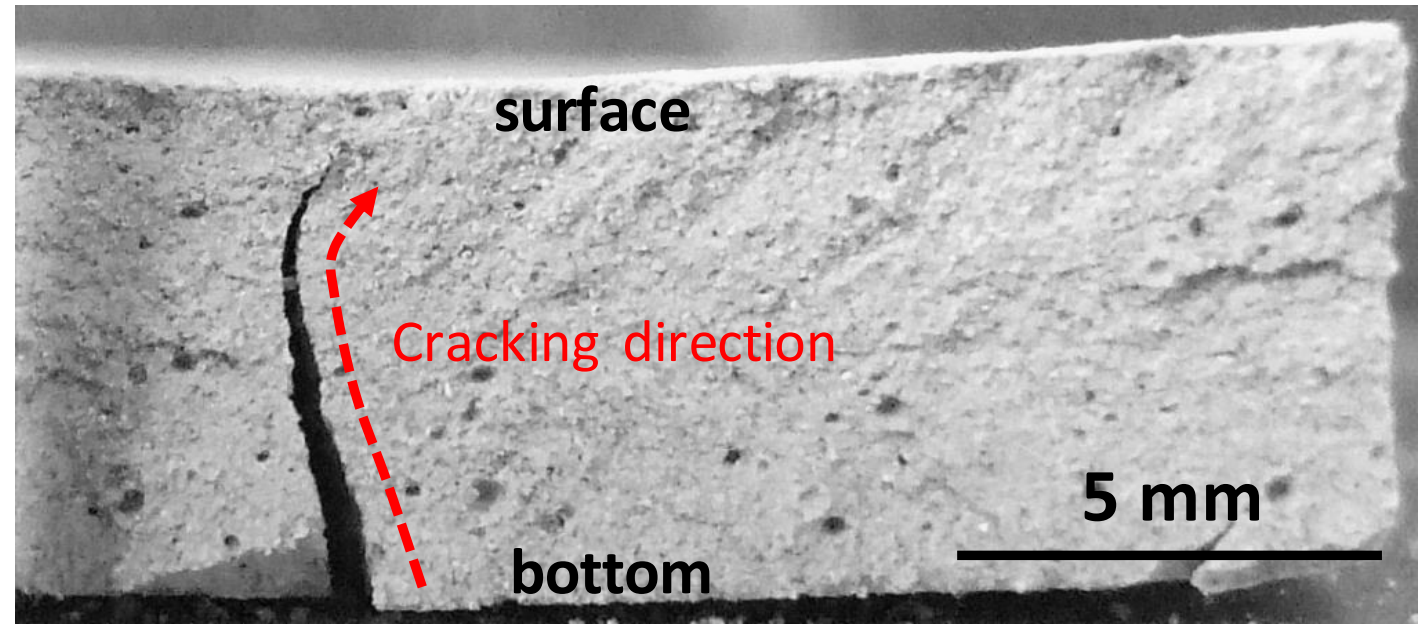

Figure 12. A crack nucleated at the bottom of the sample and propagated upwards.

4 